\title{
LA EDUCACIÓN MORAL \\ EN LAS PRIMERAS EDADES A TRAVÉS \\ DEL TEATRO ESPAÑOL DEL SIGLO XVIII Y PRIMERA MITAD DEL XIX
}

\section{Moral education in the first ages through the Spanish theatre of the eighteenth century and first half of the nineteenth}

\author{
Federico Briante Benítez \\ Universidad de Sevilla \\ Correo-e: fbriante@us.es
}

Recepción: I2 de agosto de 2020. Envío a informantes: I7 de agosto de 2020 Aceptación definitiva: 7 de septiembre de 2020

Resumen: En la España del siglo Xvin y gran parte del xix se produjo un interés extraordinario por todo lo relacionado con la educación de los más jóvenes, uno de los colectivos en los que los ilustrados depositaron sus esperanzas del tan anhelado renacer de la patria. En este sentido, el teatro, por su amplio alcance y poder didáctico, se alzaba en una plataforma de valor inigualable para la transmisión e inculcación de las nuevas ideas y corrientes pedagógicas en boga en la época. Aunque este fenómeno ya ha sido reseñado por la crítica literaria, generalmente se ha hecho en relación a obras dramáticas estelares de aquel momento como El sí de las niñas, de Moratín. Resulta necesario, pues, detenerse en otros textos teatrales quizá menos conocidos, pero que también reflejan a todas luces cómo se instó desde las tablas a la promoción de una reforma moral de la juventud española.

Palabras Clave: teatro; literatura; educación moral; jóvenes; siglos XVIII y XIX.

AвsTRACT: In Spain in the eighteenth century and much of the nineteenth century there was an extraordinary interest in the education of the youngest, one of the groups in which the enlightened placed their hopes of the long-awaited renaissance of the homeland. In this sense, the theatre, due to its wide effect and didactic power, became a platform of unequalled value for the transmission and inculcation of new ideas and pedagogical currents in vogue at that time. Although this aspect has already been studed by literary criticism, it has generally been done in relation 
to brilliant theatrical works of that time, such as El si de las niñas, by Moratín. It is necessary, therefore, to examine other perhaps less well-known theatrical texts but which also clearly show how the theatre contributed to promote a moral reform of the Spanish youth.

KEY WORDS: theatre; literature; moral education; youth; $18^{\text {th }}$ and $19^{\text {th }}$ centuries.

\section{Introducción}

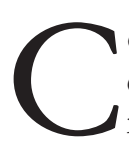

ONOCIDA ES LA IMPORTANCIA que el movimiento de las Luces confería a la educación. En el caso concreto de España, los políticos ilustrados abogaron por la educación como una de las medidas más efectivas para revertir la grave crisis económica y moral en que había quedado el país debido al mal gobierno de la saliente dinastía de los Habsburgo. El ambicioso proyecto educativo que aquellos acometieron estaba dirigido a toda la sociedad española en general, pero, muy especialmente, a la población más joven. Dada su conciencia del bien común y su preocupación por el bienestar y la prosperidad de la patria, los ilustrados habían de centrar sus esfuerzos en la formación de los más jóvenes, pues, al fin y al cabo, serían estos últimos los ciudadanos del mañana, los políticos del futuro; esa labor educativa para con los más jóvenes debía comenzar, claro está, desde las primeras edades, desde la niñez; es por ello que esta fase del ciclo vital, la niñez, empezará a cobrar, a partir del siglo XVIII, un protagonismo insospechado hasta el momento. A este respecto hay que tener en cuenta, además, otro tipo de factores, como la reducción -si bien modesta- del número de muertes ${ }^{1}$ entre los niños experimentada en la Europa setecentista, gracias a la mejora de las condiciones médicas y de higiene, tanto pública como privada, así como una mayor preocupación sobre la necesidad de cuidar la salud física como vía de perfeccionamiento moral y social. Este descenso de la mortalidad infantil hizo que, poco a poco, se dejase de considerar a la niñez como una etapa frágil, insustancial y, por tanto, no merecedora de atención ni estima. Asimismo, es en el siglo XVIII cuando se consolida definitivamente el sentimiento moderno de familia, lo que refuerza, más si cabe, el interés por la niñez ${ }^{2}$. Durante largos períodos históricos como el Medievo, el marcado carácter colectivo y social de la vida había impedido que los vínculos entre los miembros de la unidad familiar fuesen más allá de la pertenencia a un mismo linaje y de la posesión de unos bienes comunes y de unos intereses socioeconómicos, que los hijos tenían la obligación de defender y perpetuar en

Sobre este asunto concreto, véase, por ejemplo, AвARcA, Vanesa et al:: «El descenso de la mortalidad en la España interior: Albacete y Ciudad Real, I700-I895", América Latina en la Historia Económica, XXII, 3 (20I5), pp. I08-I44, https://docplayer.es/6IIO7383-El-descenso-de-la-mortalidaden-la-espana-interior-albacete-y-ciudad-real.html (consulta: 26-V-2020).

2 Como bien explica Ariès, el sentimiento de la infancia y de la niñez (que, según el historiador galo, no debe confundirse con el «afecto por los niños, sino que corresponde a la conciencia de la particularidad infantil») es indisociable del sentimiento sobre la familia [Ariés, Philippe: El niño y la vida familiar en el Antigno Régimen, Madrid, Taurus, 1987, p. 178]. 
LA EDUCACIÓN MORAL EN LAS PRIMERAS EDADES A TRAVÉS DEL TEATRO ESPAÑOL DEL SIGLO XVIII Y PRIMERA MITAD DEL XIX FEDERICO BRIANTE BENÍTEZ

el tiempo. A lo largo de un proceso lento que discurre a través de los siglos xvi y xvII, pero que no se generaliza hasta el xvinI, la «familia-linaje» propia del Medievo cede el paso a la «familia sentimental moderna»; esta última, a diferencia de la primera, deja de mirar hacia el mundo exterior y comienza a replegarse sobre sí misma. Los padres, cada vez más celosos de su intimidad, fijan su mirada en la esfera doméstica y, por ende, en los hijos, con quienes tienden a estrechar lazos. En consecuencia, a los niños ya no se les valoraba por lo que pudieran contribuir al bienestar material futuro de la familia, sino que, en cuanto máxima expresión del amor conyugal, empiezan a ser concebidos por sus progenitores como seres dignos de toda estima, cariño y cuidados.

Por todo lo dicho, podría afirmarse que la niñez (y, por extensión, la juventud) ${ }^{4}$ adquiere en el siglo xviII un estatus propio, específico. Muestra de ello es el gran número de obras pedagógicas que salieron a la luz en estos años. El propósito de nuestro trabajo consiste en analizar a través de algunas de estas obras -tratados, escritos de diversa índole y también la prensa- cuáles son las principales ideas existentes en la España del siglo xviII y primera mitad del xix sobre la educación de estas primeras edades. Asimismo, prestaremos especial atención al papel que ejerció el teatro de estos años -nacional o traducido-como catalizador de dichas ideas, habida cuenta del potencial didáctico de este género literario, como bien ha señalado, entre otros estudiosos, Guillermo Carnero 5 .

\section{La educación moral en el siglo XVIII y primera mitad del XIX}

Antes que nada, conviene aclarar el tipo de educación en el que aquí nos centraremos. Entre los autores de la época por nosotros consultados, suele haber cierto consenso en identificar tres tipos de educación destinados a los más jóvenes, a saber: la educación física, dirigida al cuidado del cuerpo; la intelectual, consistente en la adquisición de un conjunto de saberes científico-culturales (matemáticas, astronomía, lengua, literatura, geografía, historia, etc.); finalmente, la educación moral, que es en la que fijaremos nuestra atención por considerarse la más importante de todas, ya que su cometido residiría en formar el corazón y las costumbres a través de la práctica de las virtudes, lo que se presentaba, a juicio de los ilustrados, como el mejor camino para alcanzar la felicidad. Así lo cree Gaspar Melchor de Jovellanos, «el ilustrado más representativo en lo que a reformas

3 Para profundizar en las ideas y conceptos hasta aquí expuestos, remitimos a Arıès, Philippe: El niño y la vida familiar..., op. cit.

4 Cabe recordar que el término niñez era extensivo en aquella época a lo que hoy entendemos por juventud, a la luz de la definición que de dicho término ofrece el Diccionario de Autoridades: «La edad de los niños hasta los siete años: y por el común modo de hablar se extiende hasta la juventud».

Carnero, Guillermo: Estudios sobre teatro español del siglo XVIII, Zaragoza, Prensas Universitarias de Zaragoza, 1997, p. Io. 
pedagógicas se refiere» ${ }^{6}$, para quien «el estudio de la moral es el más importante y más necesario» ${ }^{7}$. En la misma línea se pronuncian otras destacadas figuras de la Ilustración, como la escritora Josefa Amar y Borbón ${ }^{8}$, el religioso menorquín Antonio Vila y Camps ${ }^{9}$ o el maestro balear Juan Mariano Picornell y Gomila ${ }^{10}$.

Una vez esbozado someramente el concepto de educación moral, cabe preguntarse quién había de impartirla y de qué modo. Para responder a estas cuestiones, es preciso recordar la visión que se tenía, por aquel entonces, del proceso configurador de la personalidad y la psicología de los más pequeños, a quienes se les concebía como una especie de pasta, extremadamente flexible, que se iba moldeando a partir de las experiencias del ambiente circundante. De esta visión, en la que se percibe la influencia del filósofo inglés John Locke, se deduce que todos los hábitos (también los morales) adquiridos por los niños dependerán de los comportamientos y acciones que estos observen en su entorno más próximo y que tenderán a imitar; esto es lo que sostienen, entre otros, el anónimo autor del «Discurso a los padres de familia sobre la educación de los hijos», publicado en el año 1787 en el Gabinete de lectura española: «Los niños irán admitiendo como una cera la impresión de las buenas máximas morales, sin necesidad de método, sino por avisos ya positivos, ya negativos, de lo que han de hacer u omitir [...] $\gg^{11}$; o el médico catalán Jaime Bonells, que dice lo siguiente:

La educación moral de los niños debe empezar desde que comienza el uso de sus sentidos. Las primeras acciones que ven, las primeras palabras que oyen, son las primeras lecciones que reciben, cuya repetición las va esculpiendo tan profundamente en su blando cerebro, que suelen quedar indelebles para toda la vida; por lo cual, si estas primeras lecciones son malas, se les corrompe ya el corazón en la niñez ${ }^{12}$.

6 Varela, Julia: «La educación ilustrada o cómo fabricar sujetos dóciles y útiles», Revista de Educación, n. ${ }^{\circ}$ extra I (1988), p. 257.

Jovellanos, Gaspar Melchor de: «Memoria sobre educación pública», en Obras publicadas e inéditas de D. Gaspar Melchor de Jovellanos, Madrid, Rivadeneyra, 1858, pp. 25I-252. Advertimos que, a lo largo del artículo, se modernizará la ortografía de las citas textuales en aras de facilitar la comprensión de las mismas, siempre que sea oportuno.

\& Amar y Borbón, Josefa: Discurso sobre la educación física y moral de las mujeres, Madrid, Imprenta de Benito Cano, I790, p. Ioo.

9 Vila y Camps, Antonio: «El noble bien educado», en Mayordomo, Alejandro y Lázaro, Luis Miguel (eds.): Escritos pedagógicos de la Ilustración (vol. I), Madrid, Ministerio de Educación y Ciencia, 1988, p. 194.

1o Picornell y Gomila, Juan Mariano: «Discurso teórico-práctico sobre la educación de la infancia», en Mayordomo, Alejandro y Lázaro, Luis Miguel (eds.): Escritos pedagógicos de la Ilustración (vol. I), Madrid, Ministerio de Educación y Ciencia, I988, p. 382.

" Anónimo: «Discurso a los padres de familia sobre la educación de los hijos», en MaYordomo, Alejandro y Lázaro, Luis Miguel (eds.): Escritos pedagógicos de la Ilustración (vol. II), Madrid, Ministerio de Educación y Ciencia, I988, p. 340.

${ }_{12}$ Bonells, Jaime: Perjuicios que acarrean al género bumano y al estado las madres que rehúsan criar a sus hijos y medios para contener el abuso de ponerlos en ama, Madrid, Miguel Escribano, I786, pp. 379-380. 
LA EDUCACIÓN MORAL EN LAS PRIMERAS EDADES A TRAVÉS DEL TEATRO ESPAÑOL DEL SIGLO XVIII Y PRIMERA MITAD DEL XIX FEDERICO BRIANTE BENÍTEZ

Es por esta razón que la mayoría de los autores del momento (Jacques Ballexerd ${ }^{13}$, Picornell y Gomila ${ }^{14}$, Jovellanos ${ }^{15}$, etc.) insisten, en sus escritos, en que no hay instrumento más idóneo para el perfeccionamiento de los críos que la conducta ejemplar de los padres; estos, los progenitores, eran, por tanto, los principales encargados de suministrar una buena educación moral a sus vástagos, algo que -como sabemos- no siempre se daba. Había padres que no estaban dispuestos a asumir tan difícil labor y preferían ingresar a sus hijos en seminarios -como reconoce Jovellanos en su Memoria sobre educación pública- o los ponían al cuidado de un ayo; hay que decir que esta última opción despierta no pocos recelos entre los ilustrados españoles, debido a la influencia -ya mencionada- de John Locke, como apreciamos en el Discurso sobre la educación física y moral de las mujeres de Amar y Borbón ${ }^{16}$. José Clavijo y Fajardo participa de esta postura crítica hacia los ayos cuando publica, en su periódico El Pensador, la carta de un lector en la que este daba cuenta de la nefasta educación recibida durante su niñez por parte de un ayo, al que califica de «interesado, ignorante, caprichoso y adulador» ${ }^{17}$. Algunos de estos atributos son los que observamos en Roque, el ayo en torno al cual gira la acción dramática de El maestro de la niña, obra de Ramón de la Cruz inspirada en la pieza homónima de Alejandro Scarlatti ${ }^{18}$. Gracias a su zalamería, Roque se ha ganado completamente la voluntad de doña Luisa hasta el punto de que la señora ha decidido encomendarle la educación de su hija Cecilia, de dieciséis años. Sabiéndose depositario de la confianza plena de doña Luisa, Roque se ha hecho poco a poco con el gobierno de toda la casa y, lejos de concentrar sus esfuerzos en la educación de Cecilia, no aprovecha sus lecciones más que para conquistar el corazón de la joven. Veamos una muestra de la peculiar lección de geografía entre Roque ${ }^{19}$ y su pupila:

$$
\begin{aligned}
& \text { Cecilia ¿Y la Grecia } \\
& \text { cae en Europa o en Asia? } \\
& \text { Roque Deja ahora eso. } \\
& \text { Cecilia No señor, } \\
& \text { que así los días se pasan, } \\
& \text { y luego se queja usted } \\
& \text { de que no soy aplicada. }
\end{aligned}
$$

${ }_{13}$ Ballexerd, Jacques: Crianza física de los niños desde su nacimiento hasta la pubertad, Madrid, Antonio Espinosa, traducción de Eugenio de Llaguno y Amírola, I787, p. 201.

${ }^{14}$ Picornell y Gomila, Juan Mariano: «Discurso teórico-práctico...», op. cit., pp. 375 y $392-$ 393.

is Jovellanos, Gaspar Melchor de: «Memoria sobre educación pública», op. cit., pp. 235-236.

16 Amar y Borbón, Josefa: Discurso sobre la educación física..., op. cit., p. 308.

17 Labrador, Carmen y Pablos, Juan Carlos de: La educación en los papeles periódicos de la Ilustración Española, Madrid, Ministerio de Educación y Ciencia, 1989, pp. 229-240.

${ }_{18}$ Véase Herrera, Jerónimo: Catálogo de autores teatrales del siglo XVIII, Madrid, Fundación Universitaria Española, I993, p. I4I.

19 El nombre de don Roque nos lleva a recordar también al personaje homónimo presente en la comedia El viejo y la niña de Moratín, otro caso paradigmático de donjuán maduro empecinado en pretender a una moza (doña Beatriz). 


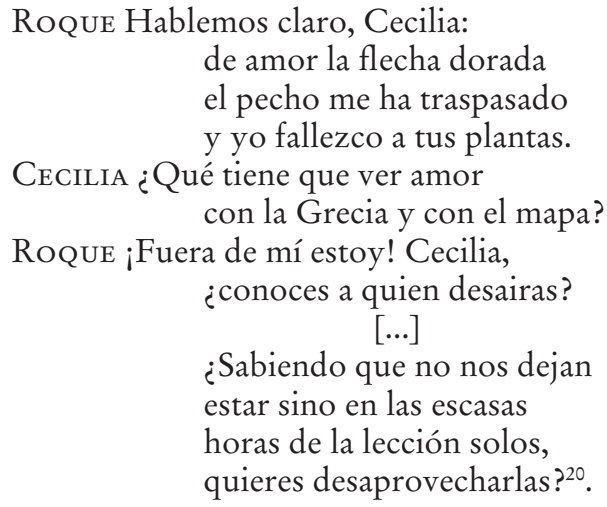

Roque Hablemos claro, Cecilia: de amor la flecha dorada el pecho me ha traspasado y yo fallezco a tus plantas.

Cecilia ¿Qué tiene que ver amor con la Grecia y con el mapa?

Roque ¡Fuera de mí estoy! Cecilia, ¿conoces a quien desairas?

$$
[\ldots]
$$

¿Sabiendo que no nos dejan estar sino en las escasas horas de la lección solos, quieres desaprovecharlas? ${ }^{20}$.

Los mismos defectos de Roque los hallamos en Trapachino, uno de los integrantes de La familia a la moda, comedia neoclásica de María Rosa Gálvez. Aunque la supuesta función de este personaje consista en dar clases de canto a Faustino, el hijo de Canuto y Madame de Pimpleas, en realidad Trapachino hace las veces de tutor del joven, ante la escasa atención que este recibe de parte de sus padres. El perfil de Trapachino es el de un hombre amante del dinero y del juego, afición que inculca a su joven alumno y con la que contrae deudas que procura saldar con el dinero de doña Guiomar, tía juiciosa de Faustino. Además, sobresale por su carácter adulador y mujeriego, pues de sus requiebros no escapa ninguna de las mujeres de la casa, desde Teresa (la criada de la familia), pasando por Madama de Pimpleas e Inés (hermana de Faustino), hasta doña Guiomar. El marqués de Altopunto nos da cuenta de este rasgo del ayo:

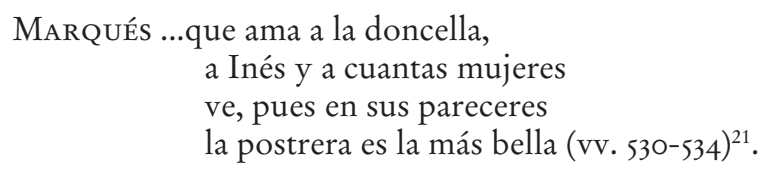

Otro tanto sucede con Octavio, el institutor que aparece en La madrastra o el padre de familias, de Valladares de Sotomayor ${ }^{22}$. Se trata de un hombre mentiroso, golfante, comilón y bebedor, tramposo, embaucador y amigo de lo ajeno, que, en vez de educar a los dos jóvenes que tiene a su cargo (los dos hijos varones de don Pancracio), los pervierte con todo tipo de distracciones, especialmente a Florindo, el hijo menor; este suele frecuentar, en compañía de Octavio, garitos donde ambos gastan alegremente a causa del juego, divertimento que el inicuo maestro procura sufragar con el dinero de doña Beatriz, la madre de Florindo -

20 Cruz, Ramón Francisco de la: El maestro de la niña, Valencia, Imprenta de José Gimeno, I826, p. 9.

${ }_{21}$ Gálvez, María Rosa: La familia a la moda, Cádiz/Salamanca, Publicaciones de la Universidad de Cádiz/Plaza Universitaria Ediciones, edición de René Andioc, 20or.

22 Véanse Herrera, Jerónimo: Catálogo de autores..., op. cit., p. 455 y Valladares de Sotomayor, Antonio: La madrastra o el padre de familias, en la Biblioteca Nacional de España (MSS/ı6413), s. a. 
LA EDUCACIÓN MORAL EN LAS PRIMERAS EDADES A TRAVÉS DEL TEATRO ESPAÑOL DEL SIGLO XVIII Y PRIMERA MITAD DEL XIX FEDERICO BRIANTE BENÍTEZ

algo análogo a lo que veíamos en Trapachino-. La irresponsabilidad de Octavio lleva a Florindo a cometer graves atropellos, por los cuales acabará pagando el muchacho, que será puesto en manos de la justicia.

Hasta aquí hemos presentado brevemente el concepto de educación moral y aclarado quiénes han de afrontarla (y quiénes no deberían) y de qué manera. A partir de este momento intentaremos subrayar los contenidos concretos de los que se componía la educación moral en el período estudiado, apoyándonos, como hasta ahora, en los escritos pedagógicos y en las obras dramáticas conservadas.

Como señalamos más arriba, el principal propósito de la educación moral consistía en inculcar a los niños la práctica de las virtudes. La primera de ellas podría ser el respeto y la obediencia a los padres. Especial importancia tiene la obediencia, entendida como la «virtud más necesaria en la sociedad doméstica y civil», en palabras del intelectual conquense Lorenzo Hervás y Panduro ${ }^{23}$. Por su parte, el ya citado maestro Picornell y Gomila se vale de las imágenes de la planta y del agricultor para plasmar este precepto de la obediencia filial en su Discurso teórico-práctico sobre la educación de la infancia: "Los hombres son en la infancia [...] como una tierna planta, pronta a recibir la dirección que se le quiera comunicar» ${ }^{24}$; más adelante, en esa misma obra, el autor mallorquín insiste en dicha idea: «El tierno arbolito, aunque nazca torcido, obedece y se dobla con facilidad a la dirección que el labrador quiere darle; pero si se le deja crecer y hacerse robusto, seguirá infaliblemente el sesgo que tomó al nacer» ${ }^{25}$. Prácticamente idénticas son las imágenes que emplea el anciano Rosmiro en la comedia La fiel pastorcita y tirano del castillo, de Fermín del Rey, cuando, en el acto III, le dice a su hija Irene que

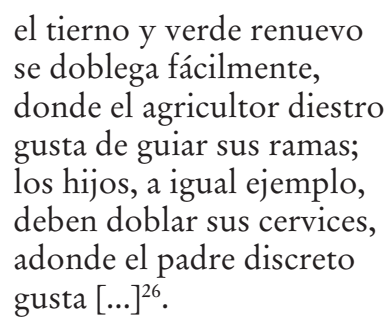

Claro está que el respeto y la obediencia, al igual que el resto de virtudes que aquí veremos, se aprenden a través del ejemplo de los padres -como ya se dijo-, de modo que si estos últimos se comportan de manera díscola y grosera, difícilmente esperarán de sus hijos un trato diferente. Esta idea es la que se intenta

${ }^{23}$ Hervás y Panduro, Lorenzo: Historia de la vida del hombre, Madrid, Imprenta de Aznar, I789, p. 285 .

${ }_{24}$ Picornell y Gomila, Juan Mariano: «Discurso teórico-práctico...», op. cit., p. 367.

25 Picornell y Gomila, Juan Mariano: «Discurso teórico-práctico...», op. cit., p. 39I.

26 Rey, Fermín del: La fiel pastorcita y tirano del castillo, s. l., s. i., I79I, p. 26. 
trasladar en la comedia Cual el padre, así es el hijo, de Félix Enciso Castrillón, en la que asistimos a los extravíos de Carlos, un joven calavera, libertino y juerguista. La lectura de la obra nos permite concluir que la indocilidad con la que actúa Carlos no es más que el fiel reflejo de la inobediencia que caracteriza al señor Belton, padre del muchacho y hombre disoluto desde su juventud, como este último reconoce con toda vanidad en el siguiente fragmento:

\author{
El bribón, según las señas, \\ se va riendo de mí. \\ No lo extraño: de la misma \\ manera admitía yo \\ de mi padre las pendencias. \\ Cada día me reñía, \\ se ponía como una fiera \\ contra mí; pero, por eso, \\ ¿qué adelantaba? Yo era \\ siempre el mismo y, además, \\ esto es una friolera ${ }^{27}$.
}

De la obediencia y respeto se deriva otra virtud no menos importante para los autores de la época: la gratitud filial; esta cualidad había de manifestarse durante toda la vida pero, muy especialmente, durante la vejez de los padres, cuando estos requieren un mayor número de cuidados. Sobre este asunto se pronuncia el anónimo autor del «Discurso a los padres de familia sobre la educación de los hijos»:

La naturaleza le ha ido dando el vigor con la misma graduación, que el tiempo os lo va quitando a vosotros [los padres] a persuasión de la envidiosa senectud. Mientras vosotros os disminuís, él [el hijo] aumenta; y siendo él y su padre una misma persona moral, tenéis de mano de la naturaleza reemplazadas las fuerzas que el tiempo os roba. El padre se sirve del hijo como de sus brazos y manos propias. Este es un auxilio u agregado de nueva fuerza a la decadencia del padre. Puesto por este medio en igualdad de duración de facultades, va caminando sin zozobra a la vejez. Llega el caso de debilitarse enteramente. El hijo suple entonces todo lo que falta, como había suplido el padre cuanto el niño no podía hacer en la infancia. Él mantiene al padre por ley de gratitud. El padre expira en los brazos del hijo. Este le cierra los ojos en paz y lo sepulta con honra ${ }^{28}$.

O Josefa Amar y Borbón, que, tras preguntarse «¿Cuántos desórdenes y pesares no ocasiona en una familia un hijo vicioso y olvidado de lo que debe a sus padres? ${ }^{29}$, afirma esto otro:

${ }_{27}$ Enciso Castrillón, Félix: Cual el padre, así es el hijo, en la Biblioteca Histórica Municipal de Madrid (Ms. Tea I-74-I2, A), s. a., f. I6r.

${ }_{28}$ Anónimo: «Discurso a los padres de familia sobre la educación de los hijos», en MaYordomo, Alejandro y Lázaro, Luis Miguel (eds.): Escritos pedagógicos de la Ilustración (vol. II), Madrid, Ministerio de Educación y Ciencia, 1988, p. 330.

29 Amar y Borbón, Josefa: Discurso sobre la educación física..., op. cit., p. I04. 
Pocas veces dejan de portarse los hijos con sus mismos padres, según el cuidado que se ha tenido de su educación. Si ha sido completo, le son obedientes toda su vida; pero si fue imperfecto, se olvida o entibia mucho el amor filial; y cuando no les den pesares muy graves, por lo menos los tratan con indiferencia, con poco respeto, y los abandonan en su vejez. Harta vergüenza es del género humano [...] que son más comunes y conocidos los ejemplos de gratitud entre los animales, que entre los hombres ${ }^{30}$.

En línea con estas ideas, el teatro de la época proporciona no pocos modelos de gratitud filial; entre los ejemplos más sobresalientes, se encuentran los de las comedias La virtud premiada o el verdadero buen bijo, traducción de Luis Moncín $^{31}$, y El amor filial, obra atribuida al conocido compositor dieciochesco Pablo Esteve y Grimau.

La primera obra nos presenta a Almanzi, un joven que vive casi en la miseria ya que debe destinar parte de su salario al sustento de su madre Isabela, que fue abandonada por el padre de Almanzi tras quedar embarazada. En el acto II de la comedia, hallamos un parlamento harto didáctico en el que Almanzi justifica el sacrificio que está haciendo por su madre en los siguientes términos:

Almanzi Sí, señor, yo os lo confieso:
no tiene 1[a] desdichada
más amparo, ni remedio
que este hijo: ¿pudiera yo
desampararla? La debo
primeramente la vida
que me dio; luego a sus pechos
mi nutrimento debí;
gastó con prudente esmero El conde muestra terneza.
el tiempo en mi educación;
sus peticiones y ruegos
sin duda que me han librado
de morir en tanto encuentro.
¿Pues pudiera ser ingrato
yo a una madre que modelo
puede ser, señor, de toda
buena madre? ¿Los preceptos
divino y humano yo
cumpliría procediendo
de otra suerte? No, señor;
os juro que solo siento
no tener muchos tesoros
con que asistirla. Os prometo
que, aunque mil veces mi vida
expusiera yo en su obsequio,

30 Amar y Borbón, Josefa: Discurso sobre la educación física..., op. cit., pp. I23-I24.

${ }_{31}$ Véase Herrera, Jerónimo: Catálogo de autores..., op. cit., p. 313. 


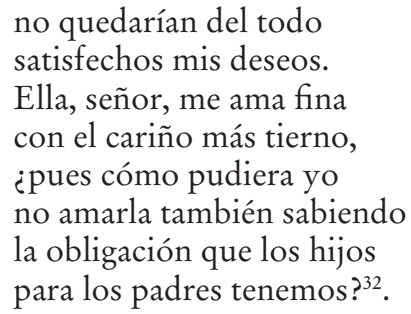

Aún más sorprendente es el caso de Joaquín, el protagonista de El amor filial. Tras la muerte del padre, la familia de Joaquín había tenido que abandonar París asediada por los acreedores y se había asentado en la posada de un pueblo. Es entonces cuando Joaquín, que tan solo cuenta con veinte años, tiene noticia de una dama rica que ofrecía una recompensa de dos mil escudos a quien descubriera al asesino de su padre. Deseoso de obtener ese dinero para socorrer a su desamparada madre, Joaquín decide entregarse a la justicia autoinculpándose falsamente del crimen; esta decisión supone un gran sufrimiento para el muchacho, no tanto por la pena capital derivada del delito, sino porque la dama rica antes aludida resulta ser Laureta, una señorita que Joaquín había conocido en París y de la que se había enamorado. Ni la fuerza de este amor ni el miedo al patíbulo impiden al muchacho continuar en su empeño de entregarse a la justicia, como él mismo declara en un largo parlamento que merece la pena reproducir, aunque solo sea parcialmente, porque resulta muy ilustrativo de lo que aquí comentamos:

Y vos, madre, madre mía,

la vida que me habéis dado

os vuelvo; no puedo hacer

más que con ella pagaros.

Ya por vos la sacrifico

al delito más villano.

Siempre que de esto me acuerdo, me olvido de los trabajos

y me sirven mis fatigas

rigurosas de descanso.

Hijos desagradecidos Se levanta.

de padres necesitados,

que negáis el alimento

a quien el ser os ha dado.

Hijos viles, que a los padres

antes de morir, osados

les priváis de aquellos bienes

que ellos mismos han ganado.

$\mathrm{Y}$ en fin, oh vosotros, hijos,

de los mortales escarnio,

que hacéis ganar el sustento

32 Moncín, Luis: La virtud premiada o el verdadero buen hijo, s. 1., s. i., s. a., p. 24. 
La gratitud se considera inherente a la condición filial y parece estar justificada, incluso, en aquellos casos en que los padres no se han comportado con sus hijos como debieran; es lo que ocurre con Enrique en la comedia $A$ padre malo, buen hijo, de Vicente Rodríguez de Arellano; pese a la crueldad con que su padre lo ha tratado en los últimos tiempos, Enrique no duda en cederle parte de la herencia que ha recibido de un tío materno cuando se entera de que su progenitor ha caído -supuestamente- en la ruina. Otro caso lo tenemos en Jacinto, en Cual más obligación es la de padre o la de juez, comedia de Valladares de Sotomayor, basada a su vez en El delincuente honrado de Jovellanos, a saber: Álvaro, padre de Jacinto y juez de profesión, había marchado en su juventud a las Indias por orden del rey; con el tiempo pensaba volver de aquellas tierras para casarse con la madre de Jacinto, pero esta falleció, de modo que sus proyectos quedaron truncados. Años después, Álvaro reaparece en la vida de su hijo, aunque en unas circunstancias bastantes adversas: Jacinto había matado al conde de Castro durante el transcurso de un desafío y el juez encargado de aplicarle al muchacho la pena capital correspondiente era Álvaro, su propio padre; lejos de lo esperable, cuando Jacinto descubre la identidad de su ajusticiador, no hace a este ningún reproche, antes bien, se muestra contento y agradecido por haber encontrado a su padre:

$$
\begin{aligned}
& \text { Don Jacinto ¿Mi padre? } \\
& \text { ¡Ay padre mío! Ya alienta } \\
& \text { mi espíritu. Ya la muerte } \\
& \text { ni me asusta, ni me altera. } \\
& \text { Después de haber pronunciado } \\
& \text { tan dulce nombre, no es ella } \\
& \text { la que ha de causarme espanto }{ }^{34} \text {. }
\end{aligned}
$$

Igualmente, León, el joven protagonista de la comedia El hijo adoptivo o El inclusero, de Félix Enciso Castrillón, fue abandonado por su familia biológica siendo muy pequeño; Luis, un viudo rico y sin hijos, recogió al niño de un hospi-

33 Esteve y Grimau, Pablo: El amor filial, Madrid, s. i., I794, p. I7.

34 Valladares de Sotomayor, Antonio: Cual más obligación es la de padre o la de juez, en la Biblioteca Histórica Municipal de Madrid (Ms. Tea I-IOI-I3, A), I777, f. I7v. 
LA EDUCACIÓN MORAL EN LAS PRIMERAS EDADES A TRAVÉS DEL TEATRO ESPAÑOL DEL SIGLO XVIII Y PRIMERA MITAD DEL XIX FEDERICO BRIANTE BENÍTEZ

cio y lo crio y educó en la práctica de las virtudes; así lo reconoce el propio León hasta en dos ocasiones en la comedia, cuando afirma que Luis «ha formado su corazón ${ }^{35}$, curiosamente la misma expresión (formar el corazón) que empleaban algunos pedagogos aquí vistos -como Picornell y Gomila- ${ }^{36}$ para definir la educación moral. La buena crianza que recibe de parte de Luis se pone de manifiesto cuando al muchacho se le presenta la ocasión de conocer a su padre biológico, Simón, al que, sorprendentemente, trata con toda dulzura, sin recriminarle ningún aspecto del pasado.

Además de las virtudes hasta ahora reseñadas, hay otras igualmente convenientes en la educación de la niñez, como la templanza, el recato, la discreción y la modestia, de las que nos hablan autores como Jovellanos ${ }^{37}$ o Antonio Vila y $\mathrm{Camps}^{38}$, entre otros. Múltiples serían los ejemplos de estas virtudes que podrían extraerse de las piezas teatrales de la época; baste mencionar, sin más, el caso de Fenisa, la protagonista de La buena muchacha, traducción de Antonio Bazo, o el de Cándida, en la comedia homónima de Trigueros.

Otro de los rasgos, quizá uno de los más conocidos, del programa pedagógico promovido desde las filas ilustradas es el encomio de la laboriosidad, pues se pensaba que la inacción abría la puerta a los vicios y entorpecía el progreso tanto individual como comunitario. En este sentido, algunos autores proponen medidas concretas para combatir el «ocio perpetuo y vicioso en que tantos jóvenes se pudren ${ }^{39}$, en palabras de Hervás y Panduro. Una de estas medidas consistiría en no acostumbrar a los hijos a depender de los criados para actividades como vestirse o asearse; de este modo, Amar y Borbón aconseja que las niñas «aprendan desde pequeñas a vestirse y calzarse por sí mismas» ${ }^{40}$. Otros, como Rodríguez de Campomanes, proponen iniciar a los niños, desde muy pronto, en el ejercicio de la lectura y de la escritura, pues «de no aplicar los niños entonces a leer y escribir, resulta que estén ociosos en aquella tierna edad y que se impresionan de especies e ideas que les perjudican demasiado, cuando llegan a ser adultos» ${ }^{41}$. Igual parecer muestra Lorenzo Hervás y Panduro ${ }^{42}$ en su Historia de la vida del hombre; este jesuita, en línea con lo apuntado años antes por el benedictino fray Benito Feijoo ${ }^{43}$, reconoce la necesidad de que las chicas no vivan en la indolencia y reciban una instrucción científica. Esta apuesta por la formación femenina también es posible testimoniarla en la prensa floreciente

35 Enciso Castrillón, Félix: El hijo adoptivo o El inclusero, en la Biblioteca Histórica Municipal de Madrid (Ms. Tea I-I94-I4, A), I8I7, ff. I6v. y 2 Ir.

36 Picornell y Gomila, Juan Mariano: «Discurso teórico-práctico...», op. cit., p. 389.

37 Jovellanos, Gaspar Melchor de: «Memoria sobre educación pública», op. cit., p. 236.

38 Vila y Camps, Antonio: «El noble bien educado», op. cit., p. 2 Iо.

39 Hervás y Panduro, Lorenzo: Historia de la vida..., op. cit., p. 286.

${ }_{40}$ Amar y Borbón, Josefa: Discurso sobre la educación física..., op. cit., p. I4I.

${ }^{41}$ Rodríguez de Campomanes, Pedro de: Discurso sobre la educación popular de los artesanos y su fomento, Madrid, Antonio de Sancha, 1775, p. I48.

${ }_{42}$ Véase Hervás y Panduro, Lorenzo: Historia de la vida..., op. cit., p. 375.

43 Véase FeIjoo y Montenegro, Benito Jerónimo: Teatro crítico universal (vol. I), Madrid, Joaquín Ibarra, 1778, pp. 325-398. 
LA EDUCACIÓN MORAL EN LAS PRIMERAS EDADES A TRAVÉS

en este siglo, como en la carta publicada en el Correo de Madrid en I787, escrita por un tal Miguel Fernández de Aguedoya:

La crianza de las jóvenes se deteriora cada día más y más. El lado de algunas madres contribuye infinito a echar a perder la vana y fantástica preocupación en que están éstas; que sus hijas no necesitan más instrucción que la de saber bailar, componerse, coser mal, y tal cual de ellas bordar, es el origen de la estupidez en que después pasan toda la vida, persuadidas a que la cara, el aire del cuerpo y el pie, son los únicos medios de merecerse cuatro elogios entre fatuos jóvenes tan simples como ellas. Descuidan con dolor las demás calidades, que en su concepto son despreciables y nada merecedoras de su atención [...] No hay hombre de talento que no guste mejor de una discreta, no siendo un monstruo, que de una tonta bien parecida, presumida por consiguiente y fastidiosa, pero para nuestra fatalidad se encuentran de éstas muchas y de aquéllas pocas, las más hacen consistir su presunción en cuatro plumas, cintas, despejo, descaro y demás subalternos de la ligereza con que piensan ${ }^{44}$.

De todo ello se hace eco, como no podía ser de otra manera, el teatro; se observa claramente en los juiciosos consejos que da Eugenio a Pepita en La señorita malcriada de Tomás de Iriarte:

Don Eugenio Porque en este mundo todos somos de todos. Quisiera

que usted cobrase aversión

al tiránico sistema

de los que, según estilo

musulmán, no consideran

a las mujeres nacidas

sino para esclavas necias

del hombre y las privan casi

del uso de las potencias.

Emplee usted bien las suyas;

verá cuánto la deleitan

ciertos estudios....

Doña Pepita Y luego

que me llamen bachillera ${ }^{45}$.

Don Eugenio Sólo pensarán así

los que ignoren que hay tareas

no menos propias de un sexo

que de otro. ¿Quién no se prenda

de una dama que reúne

a la natural viveza

el útil conocimiento 255-256.

44 Labrador, Carmen y Pablos, Juan Carlos de: La educación en los papeles..., op. cit., pp.

45 El término bachillera se usaba comúnmente para hacer referencia a «la mujer que habla mucho o sin concierto ni oportunidad» (Nuevo Tesoro Lexicográfico de la Lengua Española). 
de la historia, de la recta

moral, de geografía,

y de las más cultas lenguas

(como disfrute los buenos

libros escritos en ellas),

la afición a poesía,

dibujo, música...?46.

Volviendo al tema de la ociosidad de los más jóvenes, autores como Antonio Vila y Camps $^{47}$ o Noël-Antoine Pluche ${ }^{48}$ plantean otras recetas contra ella, como el desempeño de ciertas tareas artesanales (carpintería, agricultura, tornería, etc.), sugerencias estas que, dirigidas al estamento nobiliario -como en el caso de Vila y Camps-, nos ayudan a confirmar, por otro lado, la nueva mentalidad que se estaba fraguando en la época en lo que se refiere a la consideración de los oficios mecánicos. Esta mentalidad se hace patente en la conversación que mantienen Víctor y su hermano Mauricio en el acto I de la antedicha comedia El amor filial:

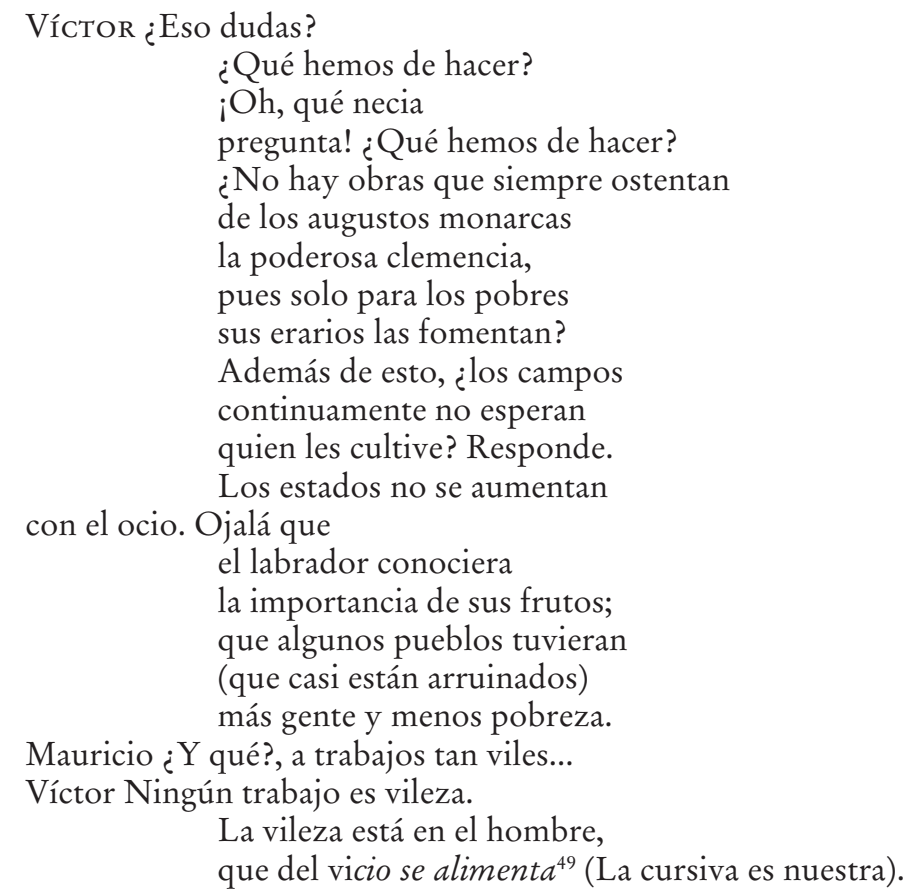

${ }^{46}$ Iriarte, Tomás de: «La señorita malcriada», en Obras de don Tomás de Iriarte, Madrid, Imprenta Real, i805, pp. 206-207.

47 Vila y Camps, Antonio: «El noble bien educado», op. cit., p. 217.

${ }_{48}$ Pluche, Noel-Antoine: Espectáculo de la naturaleza (vol. XI), Madrid, Joaquín Ibarra, traducción de Esteban Terreros y Pando, 1757, p. I6r.

49 Esteve y Grimau, Pablo: El amor filial, op. cit., p. 8. 
LA EDUCACIÓN MORAL EN LAS PRIMERAS EDADES A TRAVÉS DEL TEATRO ESPAÑOL DEL SIGLO XVIII Y PRIMERA MITAD DEL XIX FEDERICO BRIANTE BENÍTEZ

En ocasiones, la defensa de la virtud de la laboriosidad en los más jóvenes se aborda, desde el teatro, por medio de contraejemplos; es lo que apreciamos en El hijo predilecto o la parcialidad de una madre, obra de Eugenio de Tapia, en la que nos topamos con Serafín, un chico presuntuoso muy amigo de placeres, pero poco dado a los estudios y al trabajo, como se pone de manifiesto en estas palabras suyas:

Don Serafín Eso digo yo, que estudie
la gente pobre y plebeya;
pero los nobles y ricos
no, señor, que se diviertan
[...]
Por eso yo no he querido
calentarme la cabeza
en los estudios: teniendo
mayorazgo, tendré letras
yaplausos y me harán versos
poniéndome en las estrellas50.

Al igual que Serafín, tenemos el caso de Mariano en la comedia El señorito mimado, de Tomás de Iriarte. Lejos de pensar en labrarse un porvenir, Mariano pasa el día entero rodeado de malas amistades con las que derrocha el patrimonio de su familia, viviendo en la más absoluta ociosidad, pues, a su entender, «a los hombres de modo / nunca los prenden por vagos» ${ }^{51}$. Al final de la obra, y como castigo por su mala conducta, el joven es enviado a Valencia.

Tampoco hemos de olvidarnos de Pablo, el protagonista de Las máximas de un buen padre para probar a un mal bijo, de Valladares de Sotomayor. En los primeros momentos de la comedia, se nos describe la prehistoria del personaje, la de un chico que ha vivido entregado a los vicios y a todo tipo de escarceos amorosos a costa del dinero de su padre. Con la ayuda de este último y de otros personajes juiciosos como don Jaime, el joven se arrepiente de sus errores y cambia radicalmente de actitud ${ }^{52}$.

Cerraremos este amplio programa de la educación moral dieciochesca con la virtud de la moderación, que, por sus raíces clásicas, era una de las más importantes, sin lugar a dudas, en el ideario pedagógico de la Ilustración. Esta virtud se traduce en formar a los niños en la contención de sus caprichos e impulsos, en el rechazo de cualquier exceso, ya sea en el ámbito de la alimentación, del vestido o de las galas. En relación a este último punto encontramos el Comentario sobre la enseñanza de Isidoro Morales, donde este pedagogo onubense felicita al marino José Mazarredo por el hecho de que «su hijita, aun en tan pocos años, sabe juntar

so TAPIA, Eugenio de: El bijo predilecto o la parcialidad de una madre, Madrid, Imprenta de Yenes, I839, pp. 9-II.

sI IRIARTE, Tomás de: El señorito mimado, Madrid, Imprenta de Benito Cano, s. a., p. 42.

52 Valladares de Sotomayor, Antonio: Las máximas de un buen padre para probar a un mal bijo, en la Biblioteca Histórica Municipal de Madrid (Ms. Tea I-44-I9, B), 1777. 
en sus modales la honestidad con la elegancia; porque ni gusta del desaliño, ni de la demasía y afectación en el adorno ${ }^{53}$. En esta línea caminan las opiniones de Josefa Amar y Borbón ${ }^{54}$, Jovellanos (en su primera sátira «A Arnesto») ${ }^{55}$ o el anónimo autor ${ }^{56}$ de la citada carta publicada por Clavijo y Fajardo en El Pensador; todos ellos critican con dureza la afición de los jóvenes por la frivolidad y los lujos excesivos. Esta llamada a educar en la moderación es lo que subyace al acto II de La bella pastora, de Bruno Solo de Zaldívar; en esta comedia, el dramaturgo aprovecha la conducta ejemplarizante de Rosaura para hacer un encomio de las madres que educan a sus hijas en la contención y en no ser «loca[s], presumida[s] y vana[s] ${ }^{57}$. Merece la pena reproducir parte del fragmento:

$$
\begin{aligned}
& \text { Partenio Benditas sean las madres, } \\
& \text { que a sus hijas no defraudan } \\
& \text { de un patrimonio tan grande, } \\
& \text { como la prudente, sabia } \\
& \text { educación, que en el mundo } \\
& \text { no hay tesoro que más valga. } \\
& \text { MARCELA Es verdad. Rosaura barriendo. } \\
& \text { PARTENio ¡Oh, qué ejemplar } \\
& \text { tan útil, si le tomaran } \\
& \text { muchas madres con sus hijas, } \\
& \text { en lugar de las erradas } \\
& \text { máximas de dirigirlas } \\
& \text { al uso, al fausto, a la gala } \\
& \text { y otros lucimientos, que }
\end{aligned}
$$

53 Morales, José Isidoro: «Comentario de D. José Isidoro y Morales al Excmo. Sr. D. Joseph Mazarredo sobre la enseñanza de su hija», Escritos pedagógicos de la Ilustración (vol. I), Madrid, Ministerio de Educación y Ciencia, 1988, p. 285.

${ }_{54}$ «En efecto, es cosa ridícula que haya madres que contenten los deseos de sus hijas en cuantas diversiones apetecen, en la variedad de vestidos y de adornos y que no piensen en destinar una tercera parte de lo que en esto consumen en procurarles la adquisición de la verdadera sabiduría» [AMAR y Borbón, Josefa: Discurso sobre la educación física..., op. cit., p. 310].

s5 «Y tú, mísera España, tú la esperas / sobre la playa, y con afán recoges / la pestilente carga y la repartes / alegre entre tus hijos. Viles plumas, / gasas y cintas, flores y penachos, / te trae en cambio de la sangre tuya, / de tu sangre ¡oh baldón!, y acaso, acaso / de tu virtud y honestidad. Repara / cuál la liviana juventud los busca. / Mira cuál va con ellos engreída / la imprudente doncella; su cabeza, / cual nave real en triunfo empavesada, / vana presenta del favonio al soplo / la mies de plumas y de agrones, y anda / loca, buscando en la lisonja el premio / de su indiscreto afán [...]» [JovELLANos, Gaspar Melchor de: Poesias de Gaspar Melchor de Jovellanos, Oviedo, Instituto de Estudios Asturianos, edición de José Caso González, I96I, p. 239].

${ }_{56}$ «Es muy notable y digno de compasión que un padre que no perdona gasto alguno para procurar a sus hijos establecimientos brillantes, y que a costa de gastos excesivos les mantiene magníficos vestidos y equipajes y multitud de criados inútiles, sólo conozca la economía cuando se trata de buscar y atraer una o más personas que cultiven el espíritu de los mismos hijos [...] aquellos gastos se sacrifican al orgullo y la vanidad, sin tener parte en ellos el sincero deseo de hacer bien a sus hijos» [Labrador, Carmen y Pablos, Juan Carlos de: La educación en los papeles..., op. cit., p. 232 ].

57 SOlO DE ZALdívar, Bruno: La bella pastora y ciudadana en el monte y discreto labrador, en la Biblioteca Histórica Municipal de Madrid (Ms. Tea I-I2-Io, B), s. a., f. I8v. 
LA EDUCACIÓN MORAL EN LAS PRIMERAS EDADES A TRAVÉS DEL TEATRO ESPAÑOL DEL SIGLO XVIII Y PRIMERA MITAD DEL XIX FEDERICO BRIANTE BENÍTEZ

cuestan mucho y valen nada!

Rosaura Dice usted bien y yo digo Barriendo. que esas madres son madrastras ${ }^{58}$.

En el polo opuesto a Rosaura tenemos a Ceferina, La niña desdeñosa de Luciano Francisco Comella ${ }^{59}$. Ceferina representa el prototipo de la adolescente difícil, soberbia, caprichosa y amante de las modas; como suele ocurrir en otros casos vistos en estas páginas, la mala educación de la chica se debe, en gran parte, a la permisividad y escasa atención que le presta su padre Facundo. Pero quizá el ejemplo más notable de hasta qué punto de ruina moral y económica puede llegar una familia a causa del apego excesivo de sus miembros a la moda nos lo ofrece la comedia de María Rosa Gálvez anteriormente mencionada; en este caso, la oportuna intervención de doña Guiomar, personaje que representa «las luces de la razón entre tanta locura» ${ }^{60}$, evita que la pésima situación familiar vaya a mayores.

\section{Conclusiones}

Los adelantos científico-médicos, la concienciación de las autoridades y de la ciudadanía en general acerca de la importancia del cuidado de la higiene y la consolidación del sentimiento moderno de familia, entre otros factores, despertaron en el siglo XVIII un interés inusitado por las primeras edades de la persona y por todo lo relacionado con ellas, especialmente el tema educativo. A esto se suma que nos encontramos en el siglo de la Ilustración, un movimiento ideológico que confía en el poder edificante y regenerador de la educación para con toda la sociedad; más aún cuando de lo que hablamos es de la educación de los más jóvenes, a los que se les considera como «la esperanza y el nervio de la patria, [...] el plantel de los que algún día han de llegar a ser hombres y mantener el estado", en palabras de Jaime Bonells ${ }^{61}$. En consecuencia, de la educación que aquellos reciban en sus respectivos hogares dependerá el bien de todo el estado; como dice el también ilustrado Hervás y Panduro, «los hijos bien criados hacen felices las familias y la felicidad de estas es la del estado» ${ }^{62}$.

La educación física e intelectual forma a los jóvenes como «ciudadanos útiles», pero únicamente la educación moral, de la que nos hemos ocupado en este estudio, los hará «ciudadanos útiles y buenos» ${ }^{63}$, como apostilla Jovellanos en su citada Memoria sobre educación pública; y esto gracias a la práctica de las virtudes, que, según el ideario del Siglo de las Luces, constituía la principal vía para

s8 Solo de Zaldívar, Bruno: La bella pastora y ciudadana..., op. cit., ff. I8v.-I9r.

59 Comella, Luciano Francisco: La niña desdeñosa, en la Biblioteca Histórica Municipal de Madrid (Ms. Tea I-I33-6, A), s. a.

6o Trueba, Virginia: El claroscuro de las Luces. Escritoras de la Ilustración española, Barcelona, Ediciones de Intervención Cultural, 2005, p.ro3.

${ }_{61}$ Bonells, Jaime: Perjuicios que acarrean..., op. cit., p. 318.

62 Hervás y Panduro, Lorenzo: Historia de la vida..., op. cit., pp. 337-338.

${ }_{63}$ Jovellanos, Gaspar Melchor de: «Memoria sobre educación pública», op. cit., p. 251. 
alcanzar la felicidad y la fuente esencial de la nobleza humana. A este último asunto hacen referencia muchas de las obras dramáticas aquí estudiadas; así, Duling, en la comedia Cual el padre, así es el hijo, hace saber a Carlos que «la mayor nobleza / es la virtud ${ }^{\circ 4}$; en La señorita malcriada, doña Clara apunta que «no se trata / de linajes. La conducta / es la que humilla o exalta» ${ }^{65}$; y en la comedia Cual más obligación es la de padre o la de juez, Pablo afirma que «[...] el villano se hace noble / en lo noble de sus tratos» ${ }^{66}$.

A través de estos ejemplos, que vendrían a sumarse a los que se han ido desgranando a lo largo de estas líneas, es posible comprobar cómo el teatro no se mantuvo ajeno a las corrientes pedagógicas del siglo, antes bien, participó en ellas desempeñando un papel muy activo en la siempre difícil tarea de educar a los más jóvenes.

${ }^{64}$ Enciso Castrillón, Félix: Cual el padre..., op. cit., f. i2v.

65 IRIARTE, Tomás de: «La señorita malcriada», op. cit., p. I39.

${ }_{66}$ Valladares de Sotomayor, Antonio: Cual más obligación..., op. cit., f. gr. 